\title{
FENOLOGIA DE UMA COMUNIDADE DE DUNA FRONTAL NO SUL DO BRASIL
}

\author{
Tânia Tarabini Castellani' \\ César Antonio Caus' \\ Silvana Vieira ${ }^{2}$
}

Recebido em 27/03/1998. Aceito em 01/04/1999

\begin{abstract}
RESUMO - (Fenologia de uma comunidade de duna frontal no sul do Brasil). Este estudo visou descrever os padrões fenológicos em uma comunidade de dunas costeiras em Santa Catarina ( $\left.27^{\circ} \mathrm{S}\right)$, avaliar suas relações a fatores climáticos e comparar estes padrões aos de comunidades situadas em outras latitudes na costa brasileira. O estudo foi realizado com espécies da duna frontal da Praia da Joaquina. Ilha de Santa Catarina. SC. Empregou-se um método com base em frequiência. calculando-se mensalmente a ocorrência das espécies e de suas fenofases ( $n=73$ quadrados fixos de $1 \times 1 \mathrm{~m}$ ). Ocorreram espécies florescendo e frutificando ao longo de todo o ano, como observado nas comunidades situadas a menores latitudes (SP: $24^{\circ} \mathrm{S}$ e ES: $20^{\circ}$ S). O maior número de espécies em floração e frutificação ocorreu no período quente e super-úmido. De forma distinta ao que ocorre no extremo sul do Brasil (RS: $32^{\circ} \mathrm{S}$ ), observaram-se várias espécies em floração nos meses mais frios de inverno. Muitas destas. entretanto, com floração longa, mostraram redução em suas amplitudes de floração neste período. Isto pode sugerir certa limitação por temperaturas mais baixas e/ou refletir o déficit hídrico ocorrido neste período. Das 34 espécies monitoradas. 15 mostraram episódios de germinação, sendo estes mais freqüentes em meses de outono/inverno, com temperatura e umidade em declínio. A germinação no outono/inverno é discutida como estratégia utilizada pelas espécies de duna como forma de escapar das condições de maior temperatura e evapotranspiração no verão. Processos de rebrota foram registrados para 17 espécies, sendo também mais frequientes no período do outono/inverno. Restrições de umidade com ocorrência de déficit hídrico afetam tanto os eventos de floração e frutificação, como os de germinação e brotamento.
\end{abstract}

Palavras-chave - duna frontal, fenologia, floração, frutificação, germinação, sul do Brasil

ABSTRACT - (Phenology of a foredune plant community in southern Brazil). This study aimed to evaluate the patterns of plant phenology of a coastal sand dune in the State of Santa Catarina $\left(27^{\circ} \mathrm{S}\right)$. The phenological patterns were investigated in relation to climatic factors and compared to those described for other sand-dune communities on the Brazilian coast. The phenology of foredune plant species was evaluated at Joaquina Beach. Santa Catarina Island, State of Santa Catarina. A method based on the frequency of species was employed. The occurrence of each species and the phenophase presented was calculated at monthly intervals. Species were observed flowering or fruiting throughout the entire year similar to the communities at lower latitudes (São Paulo State: $24^{\circ} \mathrm{S}$ and Espírito Santo State: $20^{\circ} \mathrm{S}$ ). The greater number of species in flower and in fruit occurred in months of high rainfall and elevated temperatures. Many species were in flower in winter, different from that which occurs in the extreme south of Brazil (Rio Grande do Sul State: $32^{\circ} \mathrm{S}$ ). However, a reduction in the frequency of flowering was registered for some of these species in this period. This suggests a certain restriction by lower temperatures, as in southern Brazil, or by winter month water deficits. Among the 34 monitored species, 15 presented episodes of germination. mostly in autumn/winter, when temperature and rainfall decrease. Germination in

\footnotetext{
1 Departamento de Ecologia e Zoologia. CCB, Universidade Federal de Santa Catarina, C. Postal 476, CEP 88040-960. Florianópolis. SC, Brasil

? Instituto de Botânica, C. Postal 4005. CEP 01061-970. São Paulo. SP. Brasil
} 


\begin{abstract}
autumn/winter is discussed here as an avoidance mechanism of sand dune species from the highest temperatures and evapotranspiration conditions present in summer. Vegetative sprouting was registered for 17 species, in a similar period to that events of germination. Dry periods in August and September reduced events of flowering, fruiting, germination and sprouting.
\end{abstract}

Key words - flowering, foredune, fruiting, germination. phenology. sprouting, southern Brazil

\section{Introdução}

A fenologia de plantas tropicais ainda é tema pouco investigado (Newstron \& Frankie 1994), sendo raros os estudos em ambientes de dunas (Castillo \& Carabias 1982).

No Brasil, a fenologia de espécies de dunas foi avaliada para algumas comunidades (Hueck 1955; Cordazzo \& Seeliger 1988; Pereira et al. 1992) e populações (Costa et al. 1984, 1988a, 1988b; Mendonça \& Castellani 1993; d'Eça-Neves \& Castellani 1994; Santos \& Arruda 1995). A maioria destes estudos trata da floração e frutificação, sendo os estudos de Hueck (1955) e de Cordazzo \& Seeliger (1988) aqueles com maiores informações sobre os processos de brotamento vegetativo e de germinação.

Os estudos sobre fenologia buscam avaliar a relação entre o período de ocorrência, duração e amplitude de um evento do ciclo de vida e as condições ambientais vigentes, tais como temperatura, umidade e fotoperíodo, assim como fatores de ordem biótica (Rathcke \& Lacey 1985; Newstron \& Frankie 1994).

Ao se analisar as comunidades de dunas estudadas no Brasil, algumas diferenças referentes a períodos de floração são observadas. De forma geral, há maior florescimento de espécies nos meses de primavera e verão. Porém, no extremo sul do país (RS: $32^{\circ} \mathrm{S}$ ), a ocorrência de plantas em flor é rara nos meses de inverno (Cordazzo \& Seeliger 1988), sendo esta ocorrência maior à medida que se diminui a latitude (SP: $24^{\circ} \mathrm{S}$, ES: $20^{\circ} \mathrm{S}$ ) (Hueck 1955; Pereira et al. 1992). A baixa temperatura é um dos fatores descritos como limitantes à floração de inverno no Rio Grande do Sul, sendo a região da comunidade estudada considerada biogeograficamente de transição, entre o norte tropical e o sul temperado frio (Cordazzo \& Seeliger 1988).
Diferenças quanto à duração dos episódios de floração também são observadas para as populações destas comunidades; no Rio Grande do Sul, proporcionalmente, as espécies apresentam episódios de floração de menor duração, em relação ao observado em São Paulo (Hueck 1955; Cordazzo \& Seeliger 1988). Diferenças quanto à ocorrência de reprodução e duração dos episódios de floração e frutificação ocorrem, entretanto, entre espécies num mesmo hábitat de duna (Pereira et al. 1992). Costa et al. (1984, 1988a, 1988b) mostram que diferenças intraespecíficas em diferentes eventos do ciclo de vida podem ocorrer em função das condições dos distintos ambientes de duna.

Com o objetivo de ampliar os conhecimentos sobre a fenologia de plantas de dunas costeiras, este estudo visou descrever os padrões de floração, frutificação, germinação e aspectos de brotamento para espécies de formação de duna frontal, avaliando possíveis relações com os fatores de ordem climática. Dada a localização da área de estudo, no Estado de Santa Catarina, sul do Brasil, e às questões de restrição climática acima colocadas para comunidades no Rio Grande do Sul, figura como objetivo específico deste estudo comparar os padrões fenológicos ora obtidos àqueles das comunidades mais ao sul.

\section{Material e métodos}

O estudo foi realizado na duna frontal da Praia

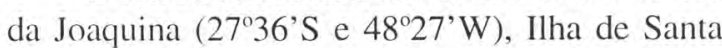
Catarina, SC. Designou-se como "duna frontal" a duna embrionária e a duna frontal propriamente dita (Fig. 1), o que compreende dois setores de vegetação na classificação apresentada em Cordazzo \& Seeliger (1993). A vegetação na área estudada é predominantemente herbácea, sendo a duna embrionária colonizada por Blutaparon 
portulacoides, Paspalum vaginatum, Panicum racemosum e Senecio crassiflorus. Na duna frontal, as gramíneas Panicum racemosum e Spartina ciliata predominam fisionomicamente, ocorrendo de forma também expressiva Ipomoea imperati, Remiria maritima, Hydrocotyle bonariensis e Conyza cf. canadensis. Arbustos de Dalbergia ecastophyllum, Dodonoea viscosa e Scaevola plumieri aparecem de forma esparsa.

Três transecções, distantes $30 \mathrm{~m}$ entre si, foram traçadas de forma perpendicular ao mar. $\mathrm{O}$ comprimento das transecções foi de 66, 73 e 76 $\mathrm{m}$, tendo-se delimitado, em cada uma, um total de 22,25 e 26 quadrados amostrais fixos $(1 \times 1 \mathrm{~m})$, respectivamente. Cada quadrado fixo foi demarcado a cada $3 \mathrm{~m}$, totalizando 73 unidades amostrais.

Em cada quadrado amostral eram registradas mensalmente as espécies presentes e suas fenofases. Seis fenofases foram determinadas: 1) presença de botão floral, 2) antese floral, 3) frutos em desenvolvimento e maduros, 4) frutos em dispersão e 5) ocorrência de germinação. A ocorrência de germinação foi constatada por evidências diretas de sementes germinando, mas principalmente pelo aparecimento de plântulas nos quadrados amostrais. Quanto aos aspectos de brotamento vegetativo (6), as espécies foram avaliadas apenas quanto à ocorrência de rebrotas, ora definidas como o surgimento de novo caule ou roseta a partir de estruturas vegetativas senescentes ou danificadas. Quando uma espécie apresentava diferentes fenofases num mesmo quadrado, todas as fases eram anotadas.

Foram calculadas, para cada mês, a frequiência de ocorrência de cada espécie nos quadrados amostrais $(n=73)$ e suas frequiências de ocorrência em diferentes fenofases (fórmula na página seguinte).

As espécies registradas nos quadrados amostrais foram coletadas e identificadas por especialistas dos Departamentos de Botânica da Universidade Federal de Santa Catarina (SC), Universidade Federal do Rio Grande do Sul (RS) e Universidade Estadual de Campinas (SP). O material encontra-se depositado na coleção de referências do Laboratório de Ecologia Terrestre/CCB/UFSC.

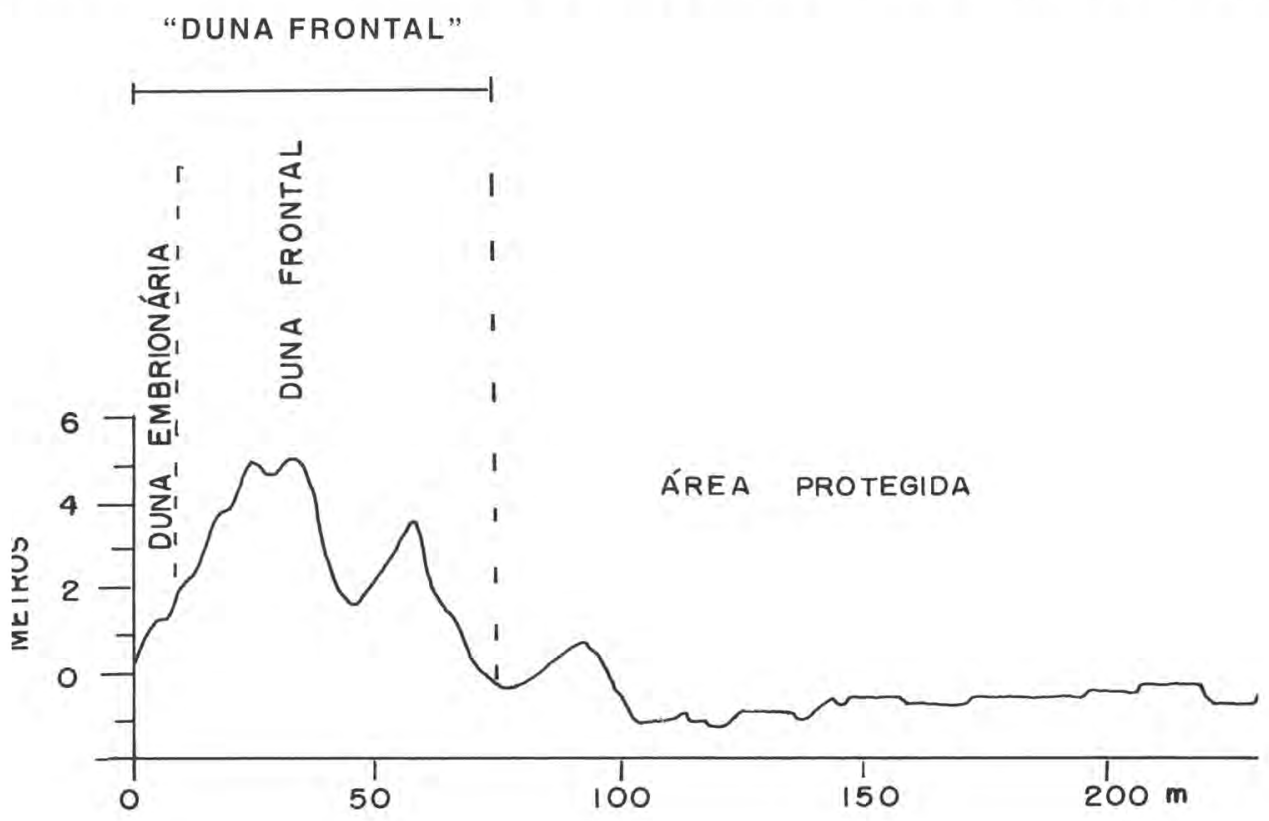

Figura 1. Perfil tranversal de um trecho das dunas da Praia da Joaquina, Ilha de Santa Catarina, SC, localizando o que foi designado como "duna frontal": a duna embrionária e a duna frontal propriamente dita, segundo a classificação de Cordazzo \& Seeliger (1993). A área "protegida ou abrigada", posterior ao setor de "duna frontal" estudado, envolve trechos de menor mobilidade e maior umidade. A base da duna embrionária foi considerada como a cota zero. 


$$
\begin{aligned}
& \text { Freqüência de ocorrência da } s p_{i}=\frac{\text { número de quadrados com a } s p_{i}}{\text { total de quadrados amostrais }(=73)} \times 100 \\
& \text { número de quadrados com a } \mathrm{sp}_{\mathrm{i}}
\end{aligned}
$$

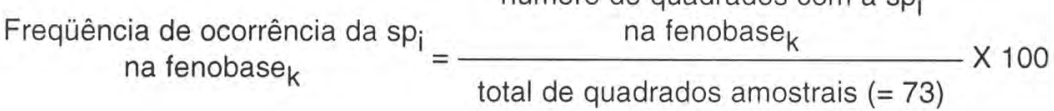

A classificação das espécies quanto à duração dos eventos fenológicos nas populações foi adaptada de Newstron \& Frankie (1994). Assim, a duração dos episódios de floração, frutificação, germinação e rebrota foram descritos como: 1) duração breve (<1 mês); 2) duração intermediária (=1 a $<5$ meses) e 3 ) duração longa (=5 meses). Eventos observados em apenas uma amostragem foram considerados como de duração breve. Fenogramas individuais foram construídos para as espécies que apresentaram frequiências de ocorrência superiores a $25 \%$ nas parcelas amostrais, sendo estas analisadas quanto ao período de maior amplitude de floração e demais fenofases.

O clima da região de Florianópolis é do tipo Cfa, mesotérmico úmido (Souza et al. 1991/1992). Dados climatológicos fornecidos pelo Destacamento de Proteção ao Vôo de Florianópolis, para o período de 1984 a 1994 , mostram temperatura média anual de $21^{\circ} \mathrm{C}$ e pluviosidade anual de $1.563 \mathrm{~mm}$. A temperatura média mais baixa ocorre em julho $\left(16,19^{\circ} \mathrm{C}\right)$ e as mais altas, em janeiro e fevereiro $\left(25,04^{\circ} \mathrm{C}\right.$ e $\left.25,29^{\circ} \mathrm{C}\right)$. As chuvas ocorrem ao longo de todo o ano, com maiores concentrações em janeiro e fevereiro, e menores índices médios em junho, julho e agosto. O diagrama climático médio para estes anos (Fig. 2a) sugere a existência de dois períodos distintos: 1) período quente e super-úmido, de outubro a abril (temperaturas médias mensais $>20^{\circ} \mathrm{C}$ e pluviosidade $>100 \mathrm{~mm}$ ) e 2) período relativamente mais frio (temperaturas $<20^{\circ} \mathrm{C}$ ), com tendência de redução de pluviosidade (pluviosidade < $100 \mathrm{~mm}$ ), de maio a setembro. Apesar dos valores médios não mostrarem episódios de déficit hídrico, análises de diagramas anuais de forma seqüencial mostram episódios de déficits em nove dos anos apresentados, sendo estes mais freqüêntes de maio a agosto (Fig. 2b).

A Fig. 2c mostra o diagrama climático para a região de Florianópolis nos meses de estudo (março de 1994 a fevereiro de 1995). O período mais frio e de menor umidade (2) ocorreu mais tardiamente, de junho a setembro, com déficit hídrico em agosto e setembro e temperatura média mais baixa em agosto. O período quente e superúmido (1) ocorreu de dezembro a maio, e os meses de outubro e novembro foram de temperaturas em elevação $\left(>20^{\circ} \mathrm{C}\right)$ mas de umidade abaixo de $100 \mathrm{~mm}$, ora designado como período de transição (3). Estes três períodos foram descritos e utilizados neste estudo para a auxiliar na descrição e análise dos eventos fenológicos.

\section{Resultados}

Fenologia da floração - Trinta e quatro espécies foram registradas e acompanhadas nos quadrados amostrais, das quais três não floresceram (Tab. 1). O maior número de espécies em antese floral ocorreu no período quente e super-úmido, nos meses de fevereiro e março (18 e 19 , respectivamente), e o menor em setembro ( 8 espécies), no período frio com redução de umidade (Tab. 2).

Seis espécies tiveram floração de breve duração e no período quente e super-úmido (Tab. 2). Das 10 espécies com floração de duração intermediária, a maioria também floresceu de dezembro a maio, porém, outros padrões foram observados: Senecio crassiflorus floresceu no período frio com redução de umidade, apresentando pico de floração em setembro; Andropogon cf. arenarius e Gamochaeta americana floresceram a partir de outubro, no período de 
A) $1984-1994$

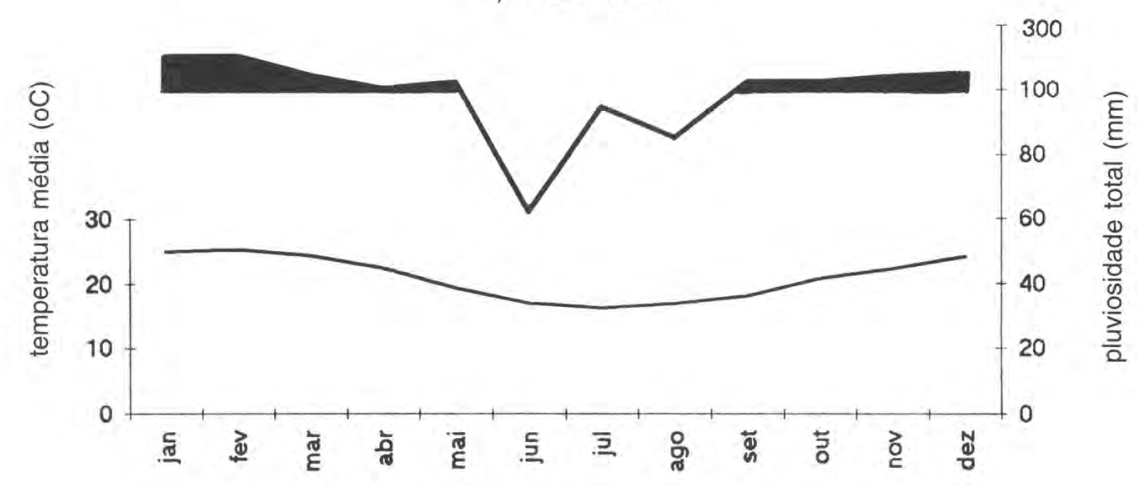

B) Seqüência anual 1984-1994

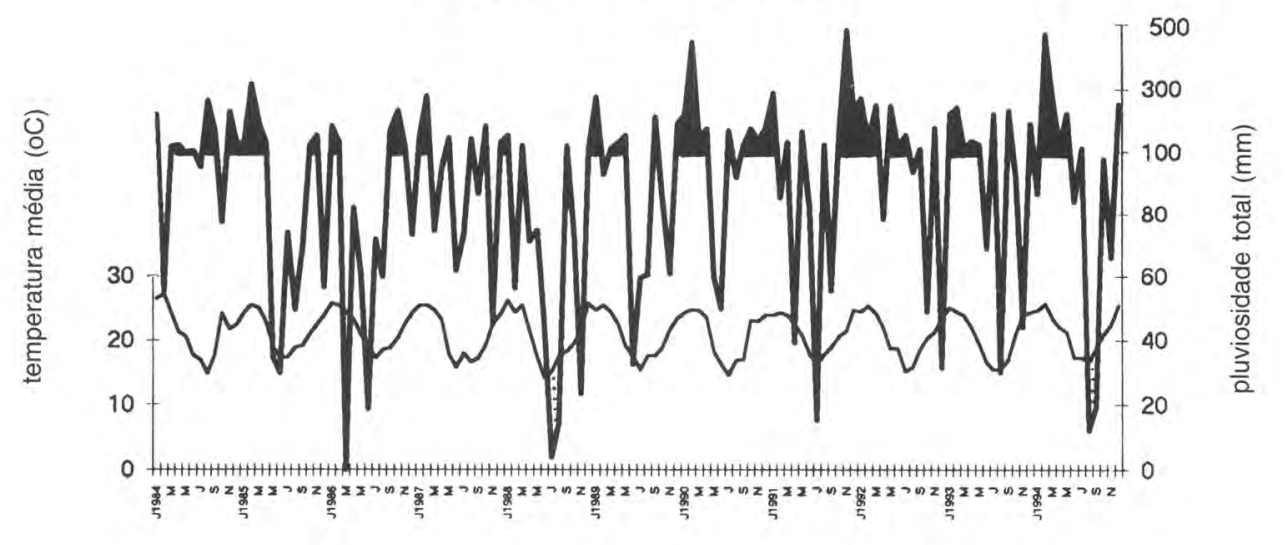

C) Período de estudo

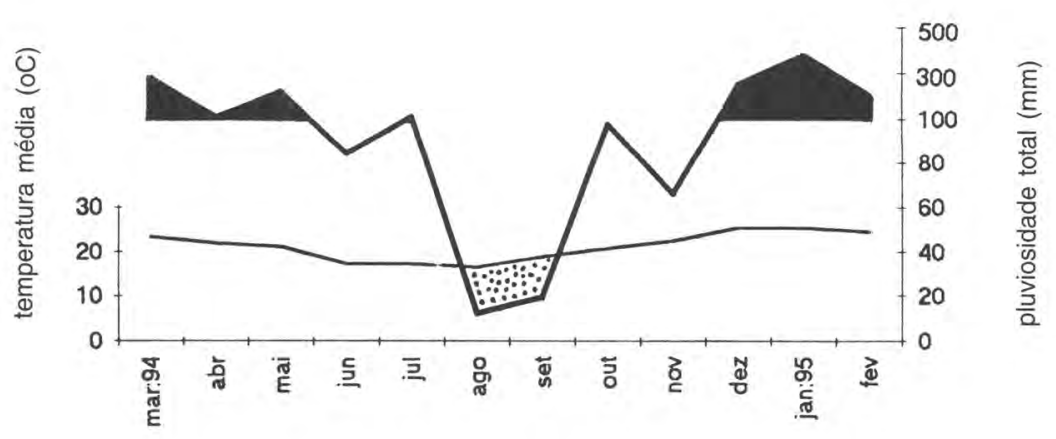

Figura 2. Diagramas climáticos para a região de Florianópolis: A) diagramas com valores médios mensais de temperatura e pluviosidade para o período de 1984 a 1994; B) diagramas anuais seqüenciais de 1984 a 1994 e C) diagrama para o período de estudo (março de 1994 a fevereiro de 1995). Os diagramas foram elaborados segundo procedimentos em Walter (1986), que estima, a cada $10^{\circ} \mathrm{C}$ de temperatura, perda de umidade de $20 \mathrm{~mm}$ por evapotranspiração. Período super úmido (precipitação $>100 \mathrm{~mm}$ ); $\square$ Período úmido (temperatura < precipitação < 100mm) e $\square$ Déficit hídrico (precipitação < temperatura). Fonte: Destacamento de Proteção ao Vôo, Florianópolis, SC. 
Tahela I. Espécies amostradas na duna frontal (Praia da Joaquina. Itha de Santa Catarina, SC) e suas frequiências de ocorrência (\%) mínima e máxima ao longo do período de estudo ( $n=73$ quadrados permanentes). * Espécies que não se reproduziram ao longo do estudo

\begin{tabular}{|c|c|c|}
\hline Espécie & F. max. & F. min. \\
\hline Ipomoea imperati (Vahl) Grisebach & 75.34 & 71,23 \\
\hline Remiria maritima Aubl. & 75.34 & 69.86 \\
\hline Panicum racemosum Spr. & 75.34 & 63.01 \\
\hline Hydrocotyle bonariensis Lam. & 69.86 & 50,68 \\
\hline Conva cf. canadensis (L.) Cronq. & 64.38 & 34.25 \\
\hline Polygala cyparissias St.- Hil. \& Moquin & 47.94 & 32,88 \\
\hline Spartina ciliata Brong. & 47.94 & 32.88 \\
\hline Oenothera molissima $\mathrm{L}$. & 43.83 & 34,25 \\
\hline Porophylum ruderale (Jacq.) Cass. & 43.83 & 27.40 \\
\hline Petumia littoralis Smith \& Downs & 42,46 & 24,66 \\
\hline Cenchrus ef. incertus M. A. Curtis & 41.09 & 32,88 \\
\hline Canavalia rosea (Sw.) DC. & 41.09 & 24.66 \\
\hline Orypetalum cf. banksii R. \& S. & 36.97 & 23,29 \\
\hline Chloris retusa Lagasca & 35.62 & 26,03 \\
\hline Senecio crassiflorus (Poir.) DC. & 34.25 & 23,29 \\
\hline Blutaparon portulacoides (St.- Hil.) Mears & 26.03 & 12,33 \\
\hline Gamochata anericana (Mill). Wedd. & 26.03 & 1,37 \\
\hline Indeterminada $1 *$ & 23.29 & 12,33 \\
\hline Paspalum vaginatum Sw. & 21.92 & 6,85 \\
\hline Digitaria connivens (Trin.) Mez. & 20.55 & 12,33 \\
\hline Ipomoea pes-caprae (L.) R. Brown & 13.70 & 5,48 \\
\hline Cardionema ramosissima* (Weinm.) Nelson \& Macbride & 8.22 & 1,37 \\
\hline Noticastrum malmei Zardini & 6.85 & 0,00 \\
\hline Schizachyrium sp. & 5.48 & 4,11 \\
\hline Scaerola plumieri (L.) Vahl & 4.11 & 4,11 \\
\hline Dalbergia ecastophyllum (L.) Taub. & 4.11 & 2,74 \\
\hline Stylosamthes viscosa $\mathrm{Sw}$ & 4.11 & 1,37 \\
\hline Eragrostis lugens Nees & 2.74 & 1,37 \\
\hline Solanum americanum Miller & 2.74 & 1,37 \\
\hline Androtrichum trigynum (Spr.) Pfeiff. & 1.37 & 1,37 \\
\hline Baccharis radicans DC. & 1.37 & 1,37 \\
\hline Epidendrum fulgens * Brongn. & 1.37 & 1.37 \\
\hline Andropogon cf. arenarius Hack. & 1.37 & 0.00 \\
\hline Setaria geniculata (Lamark) Beauv. & 1.37 & 0,00 \\
\hline
\end{tabular}

transição (Tab. 2 e Fig. 3). Neste grupo, Panicum racemosum. Spartina ciliata e Remiria maritima foram as espécies de maior frequiência (Tab. 1). Todas floresceram no período quente, porém com baixa ocorrência de plantas férteis em $P$. racemosum e $S$. ciliata, diferindo de $R$. maritima, com floração intensa em fevereiro (Fig. 3).

Quinze espécies apresentaram floração de longa duração, com quatro destas em flor e botão ao longo de todo o período de estudo (Tab. 2). Neste grupo, em relação aos anteriores, maior número de espécies apresentou-se em flor na estação mais fria. Várias espécies, entretanto, mostraram forte redução na amplitude de floração durante este período; Oenothera molissima, Ipomoea imperati, Hydrocotyle bonariensis e Polygala cyparissias, com floração de 11 a 12 meses, mostraram baixa frequiência de ocorrência de plantas em flor e botão nos meses de junho, julho e agosto (Fig. 4). De forma contrastante, Oxypetalum cf. banksii, que floresceu o ano todo, apresentou maior frequiência de plantas férteis de julho a setembro (Fig. 4).

Dentre as espécies com floração longa e maiores frequiências de ocorrência, três padrões foram observados quanto ao período de maior amplitude de floração: 1) floração mais intensa no período frio com redução de umidade, como 
Tahela 2. Fenograma para floração das espécies de duna firontal da Praia da Joaquina. Florianópolis, SC. As espécies estão organizadas de acordo com a duração dos episódios de lloração na população; hreve $(<1$ mês). intermediária $(\geq 1$ a $<5$ meses) e longa ( $\geq 5$ meses $)$

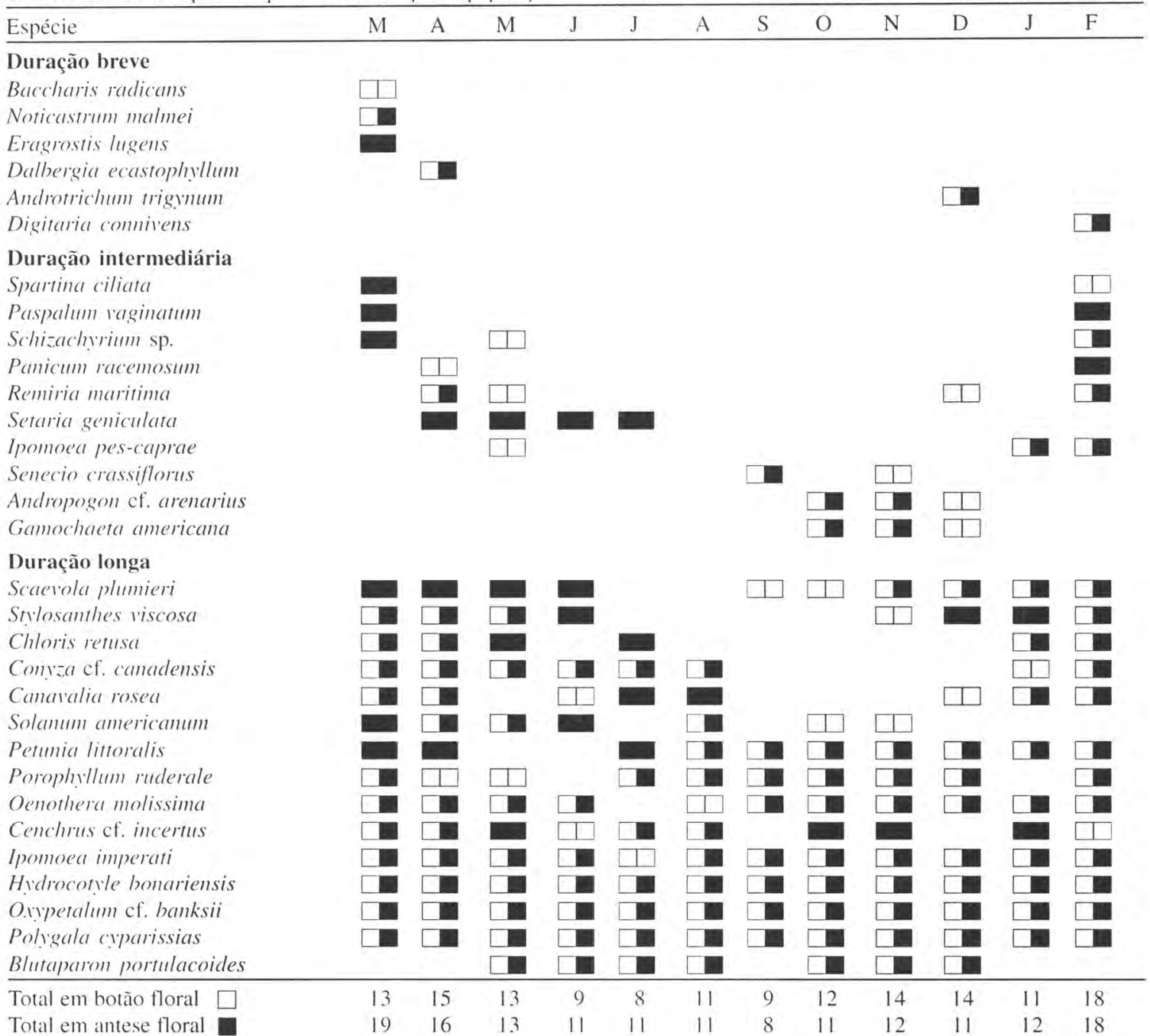

descrito para Oxypetalum cf. banksii; 2) no período de transição, como em Petunia littoralis, Polvgala cyparissias e Blutaparon portulacoides, e 3) no período quente e super-úmido, como em Chloris retusa, Conyza cf. canadensis, Canavalia rosea, Oenothera molissima, Ipomoea imperati e Hydrocotyle bonariensis. Porophyllum ruderale mostrou dois momentos de elevada floração na população, um no período de transição e outro no quente e super-úmido. Comportamento bastante irregular ocorreu com Cenchrus cf. incertus (Fig. 4).
Fenologia da frutificação - Das 34 espécies acompanhadas, 30 frutificaram. Das espécies que floresceram, apenas Baccharis radicans não desenvolveu frutos nas parcelas amostrais. A maior ocorrência de espécies em frutificação foi de fevereiro a maio, no período quente e superúmido, com maior número em fevereiro e abril (19 e 21 , respectivamente). O menor número de espécies em frutificação ocorreu em julho e agosto (10 e 9, respectivamente) (Tab. 3).

Seis espécies mostraram episódios de frutificação de breve duração na população e 10 
Tabela 3. Fenograma para frutificação das espécies de duna frontal da Praia da Joaquina. Florianópolis. SC. As espécies estão organizadas de acordo com a duração dos episódios de frutificação na população: breve $(<1$ mês). intermediária $(\geq 1$ a $<5$ meses) e longa $(\geq 5$ meses)

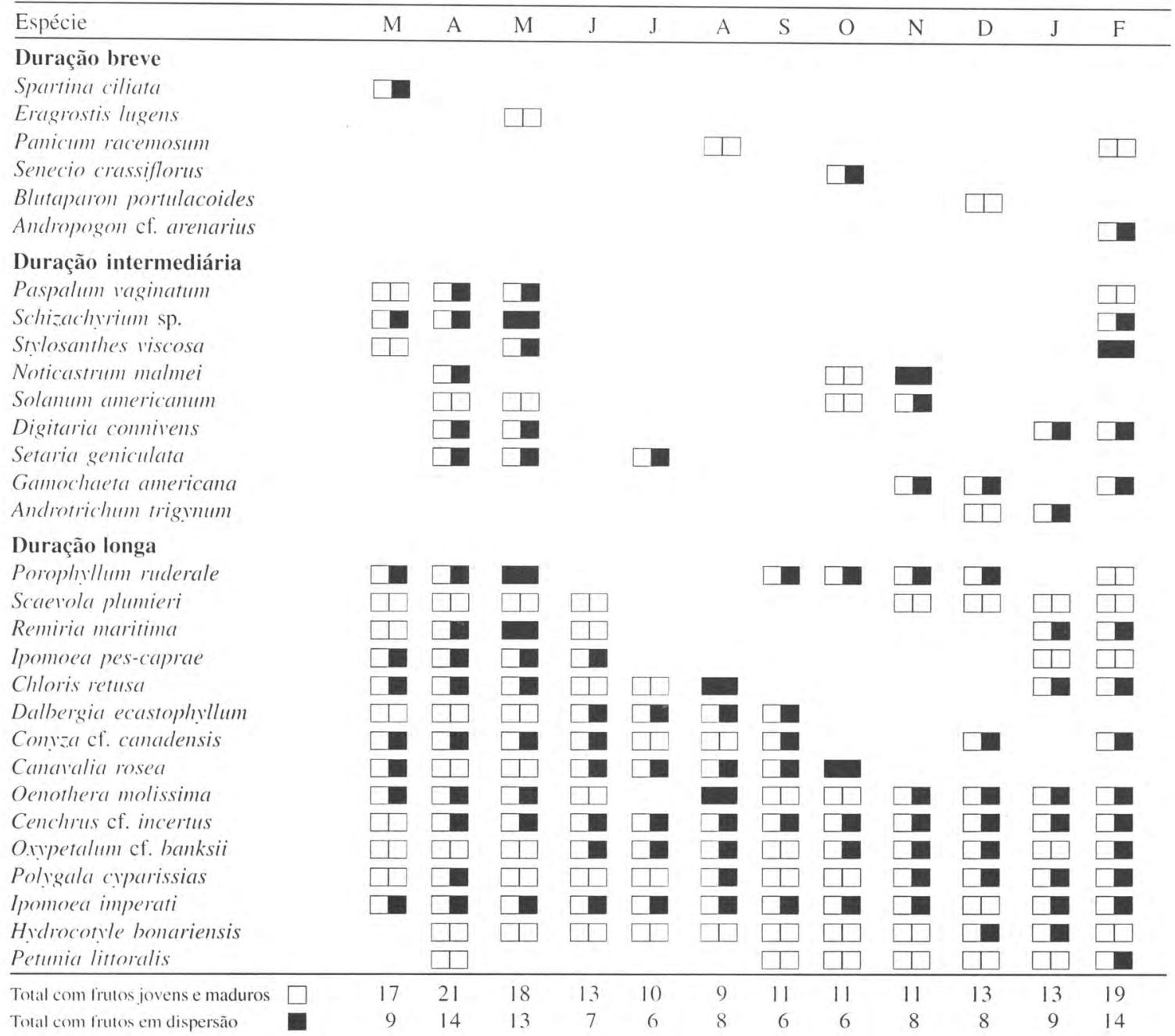

espécies, duração intermediária. Nestas, frutificação no período mais quente foi relativamente mais frequiente. Dentre as espécies de maior ocorrência, Senecio crassiflorus e Gamochaeta americana frutificaram no período de transição; Spartina ciliata e Panicum racemosum no período quente e super-úmido (Tab. 3 e Fig. 3).

As espécies com frutificação de longa duração mostraram três padrões quanto à amplitude: 1) frutificação mais intensa no período frio, com redução de umidade, Oxypetalum cf. banksii; 2) no período de transição, Petunia littoralis e Polygala cyparissias e 3) no período quente e super-úmido, Chloris retusa, Conyza cf. canadensis, Remiria maritima, Oenothera molissima. Cenchrus cf. incertus, Hydrocotyle bonariensis, Canavalia rosea e Ipomoea imperati, as duas últimas com elevadas freqüências de ocorrência de plantas em frutificação e dispersão expandindo-se para o período mais frio. Porophyllum ruderale mostrou maiores amplitudes de frutificação também em dois momentos, no período de transição e no quente e super-úmido (Figs. 3 e 4). 


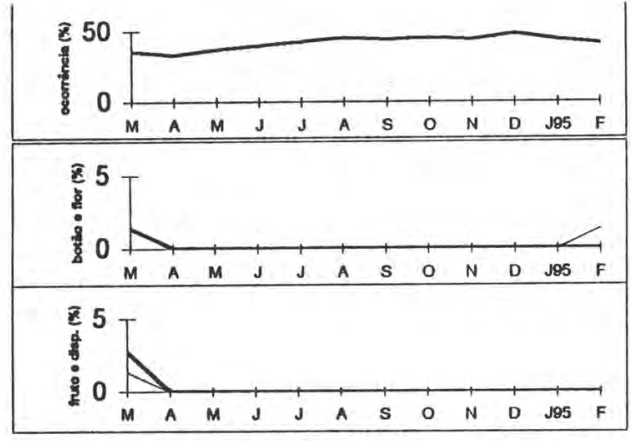

Remiria maritima

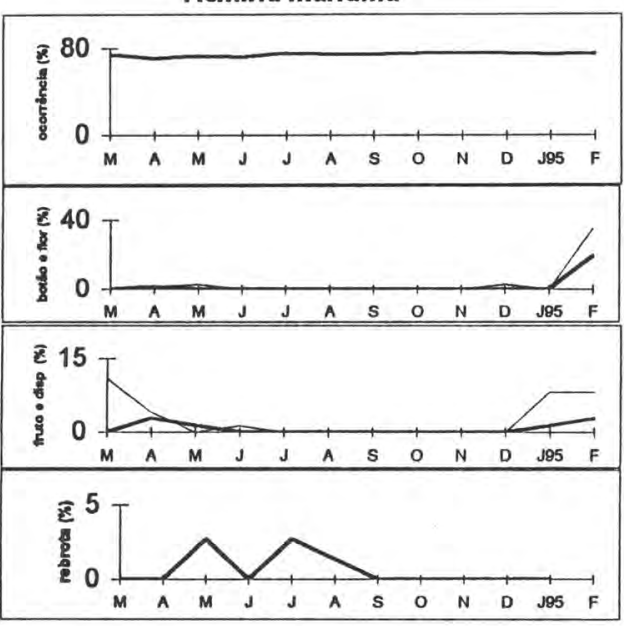

Gamochaeta americana

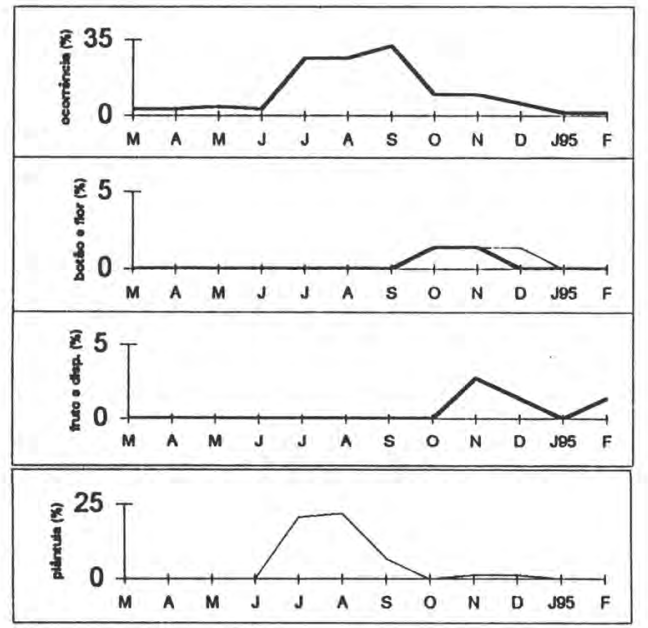

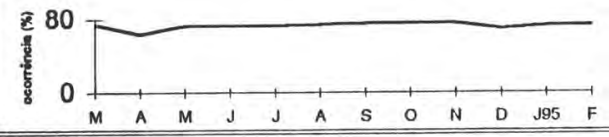
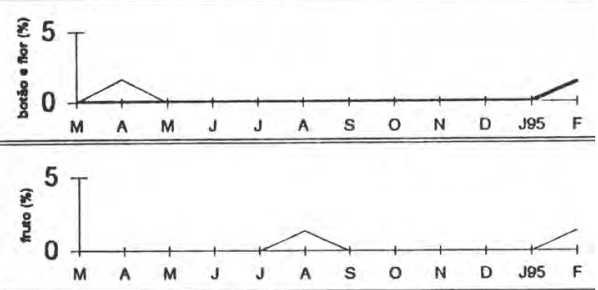

Senecio crassiflorus
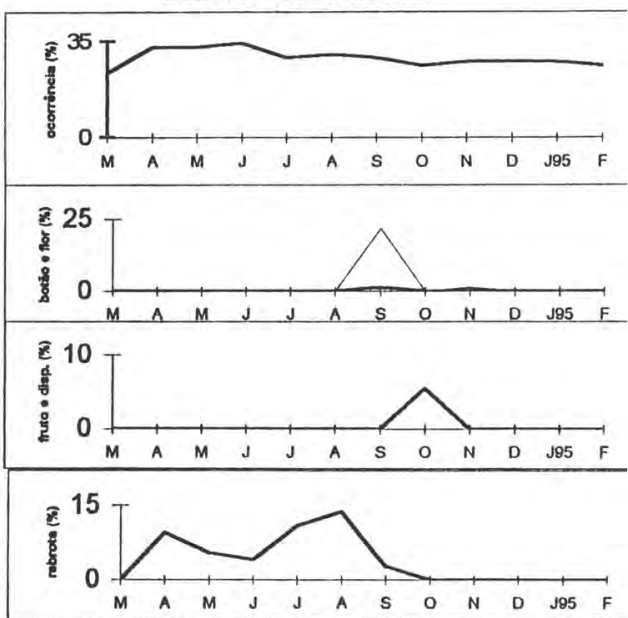

Figura 3. Fenograma para espécies de maior frequêencia de ocorrência (> 25\%) e com episódios de floração de duração intermediária, duna frontal da Praia da Joaquina, Florianópolis, SC. As figuras apresentam a frequiência de ocorrência de cada espécie nas diferentes fenofases: floração (botão — e ântese floral — ); frutificação (frutos em desenvolvimento e maduros — e frutos em dispersão — ); germinação (expresso em freqüência de ocorrência de plântulas _ _ ) e eventos de rebrota — . 
Tahela 4. Fenograma para germinação das espécies de duna frontal da Praia da Joaquina. Florianópolis, SC. As espécies estão organizadas de acordo com a duração dos episódios de germinação na população: breve $(<1$ mês). intermediária $(\geq 1$ a $<5$ meses) e longa ( $\geq 5$ meses)

\begin{tabular}{|c|c|c|c|c|c|c|c|c|c|c|c|c|}
\hline Espécie & M & A & $\mathrm{M}$ & $\mathrm{J}$ & $\mathrm{J}$ & A & $\mathrm{S}$ & $\mathrm{O}$ & $\mathrm{N}$ & $\mathrm{D}$ & $\mathrm{J}$ & $\mathrm{F}$ \\
\hline $\begin{array}{l}\text { Duração breve } \\
\text { Cancrivalia rosea } \\
\text { Ipomoea pes-caprae } \\
\text { Noticastrum malmei } \\
\text { Iponnoa imperati } \\
\text { Petunia littoralis }\end{array}$ & & & & & & & & & & & & \\
\hline $\begin{array}{l}\text { Duração intermediária } \\
\text { Blutaparon portulacoides } \\
\text { Oxypetalum cf. banksii } \\
\text { Cardionema ramosissima }\end{array}$ & & & & & & & & & & & & \\
\hline $\begin{array}{l}\text { Duração longa } \\
\text { Oenothera molissima } \\
\text { Porophyllum ruderale } \\
\text { Conva cf. canadensis } \\
\text { Cenchrus cf. incertus } \\
\text { Chloris retusa } \\
\text { Pol,gala cyparissias } \\
\text { Gamochacta anericana }\end{array}$ & & & & & & & & & 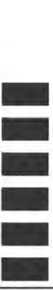 & & & \\
\hline Total com episódios de germinação & 0 & 2 & 8 & 9 & 2 & 9 & 4 & 6 & 6 & 5 & 1 & 1 \\
\hline
\end{tabular}

Fenologia da germinação - Foram registradas plântulas e sementes germinando para 15 espécies (Tab. 4). Plântulas de Senecio crassiflorus e de Stylosanthes viscosa foram também observadas em junho, porém, fora dos quadrados amostrais.

Os episódios de germinação ocorreram para maior número de espécies de maio a agosto, envolvendo o final do período quente e superúmido e parte do período frio. Isto representa meses com temperatura e pluviosidade em declínio, com déficits hídricos em agosto e setembro, quando cessou a germinação em algumas espécies. Os meses de janeiro a abril foram os de menor ocorrência de germinação (Tab. 4).

Cinco espécies mostraram episódios breves de germinação na população, três tiveram episódios de duração intermediária e sete espécies, longos períodos com germinação. Dentre as espécies com maior frequiência de ocorrência, o processo de germinação foi mais expressivo para Gamochaeta americana, Chloris retusa, Conyza cf. canadensis, Porophyllum ruderale e Oenothera molissima. A maior frequiência de ocorrência de plântulas nestas populações foi de junho a agosto, sendo que para Porophyllum ruderale valores elevados ocorreram desde maio. Para Gamochaeta americana, a emergência e o estabelecimento de plântulas gerou aumento considerável na frequiência de ocorrência da espécie, que aumentou de $1,37 \%$ em junho para $31,9 \%$ em setembro (Figs. 3 e 4 ).

Aspectos fenológicos de brotamento vegetativo - Das 34 espécies monitoradas, 17 apresentaram ramos e rosetas originadas por rebrota. Tal processo ocorreu em maior número de espécies de abril a outubro, com redução em setembro (Tab. 5). Assim como para a germinação, este período envolveu o final da estação quente e super-úmida e o período mais frio, com redução de umidade.

Em três espécies os episódios de brotamento foram breves, em oito de duração intermediária e, em seis espécies, de duração longa na população (Tab. 5). Dentre as espécies de maior frequiência de ocorrência, o brotamento de novos ramos foi mais expressivo em Senecio crassiflorus, Chloris retusa, Conyza cf. canadensis e Oenothera molissima. Em Senecio crassiflorus a rebrota foi mais expressiva em julho e agosto e associada a restabelecimento após erosão marinha. Em Chloris retusa esta ocorreu em maio e junho, e em Conyza cf. canadensis, em julho, agosto e janeiro, com surgimento de novas rosetas bastante evidente após a floração e 


\section{Chloris retusa}

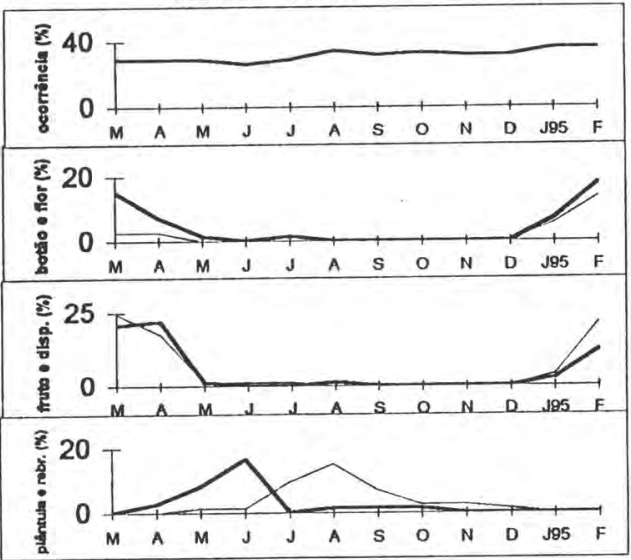

Canavalia rosea

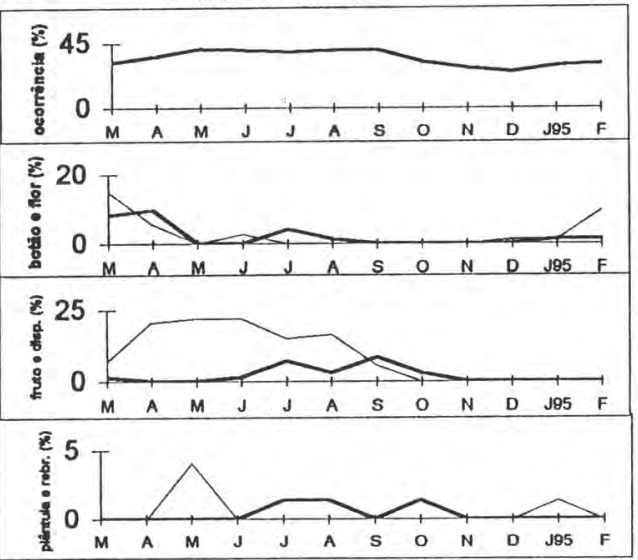

Porophyllum ruderale
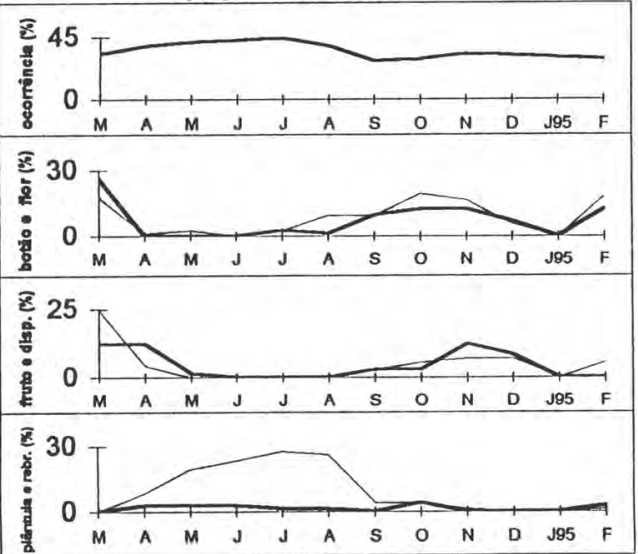

Conyza cr. canaqensıs

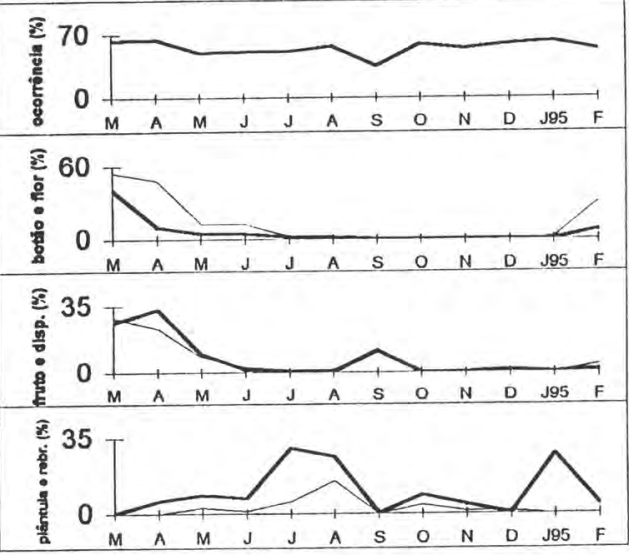

Petunia littoralis

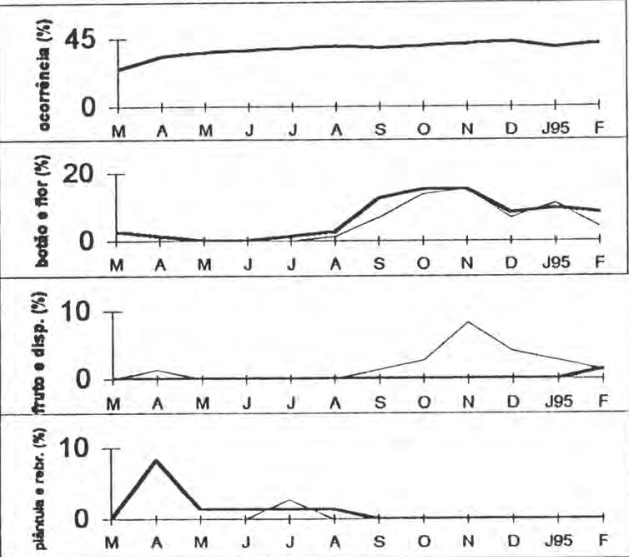

\section{Oenothera molissima}
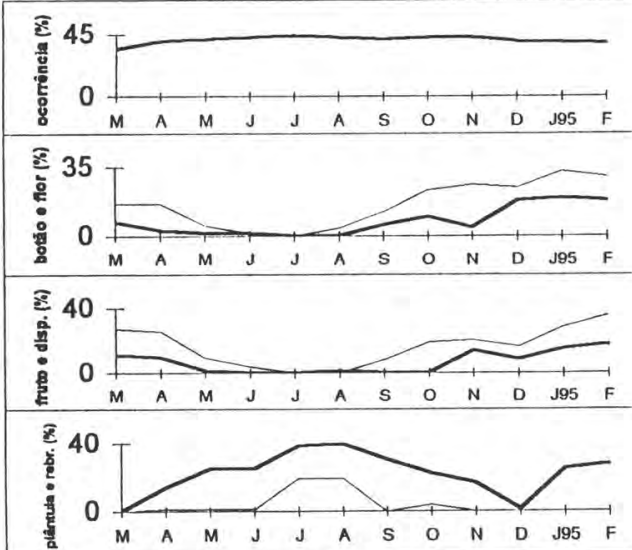

Figura 4. Fenograma para espécies de maior freqüência de ocorrência (> 25\%) e com episódios de floração de duração longa, duna frontal da Praia da Joaquina, Florianópolis, SC. As figuras apresentam a freqüência de ocorrência de cada espécie nas diferentes fenofases: floração (botão — e ântese floral — ); frutificação (frutos em desenvolvimento e maduros — e frutos em dispersão — ); germinação (expresso em frequiência de ocorrência de plântulas — ) e eventos de rebrota — 

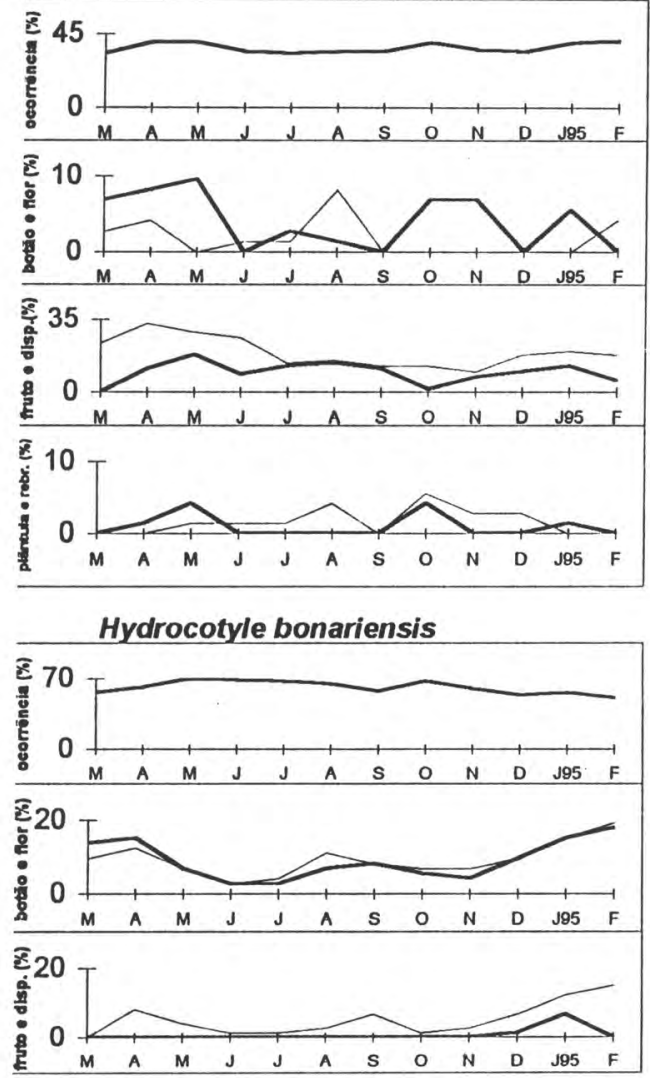

\section{Poligala cyparissias}

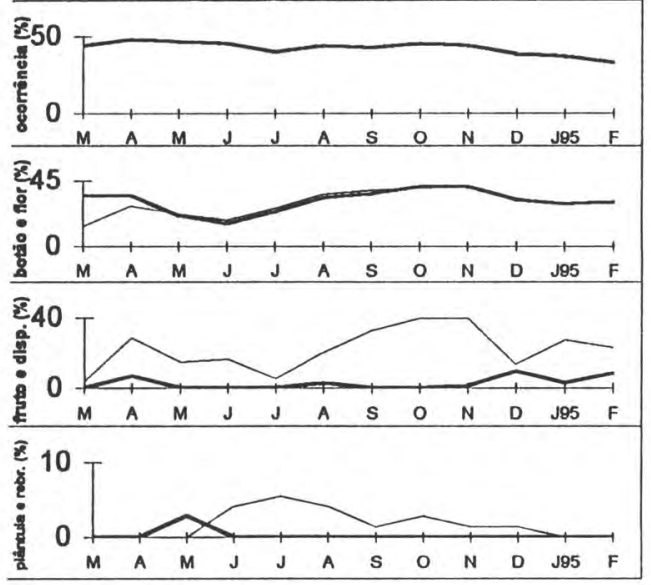

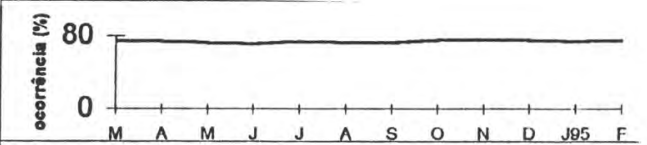
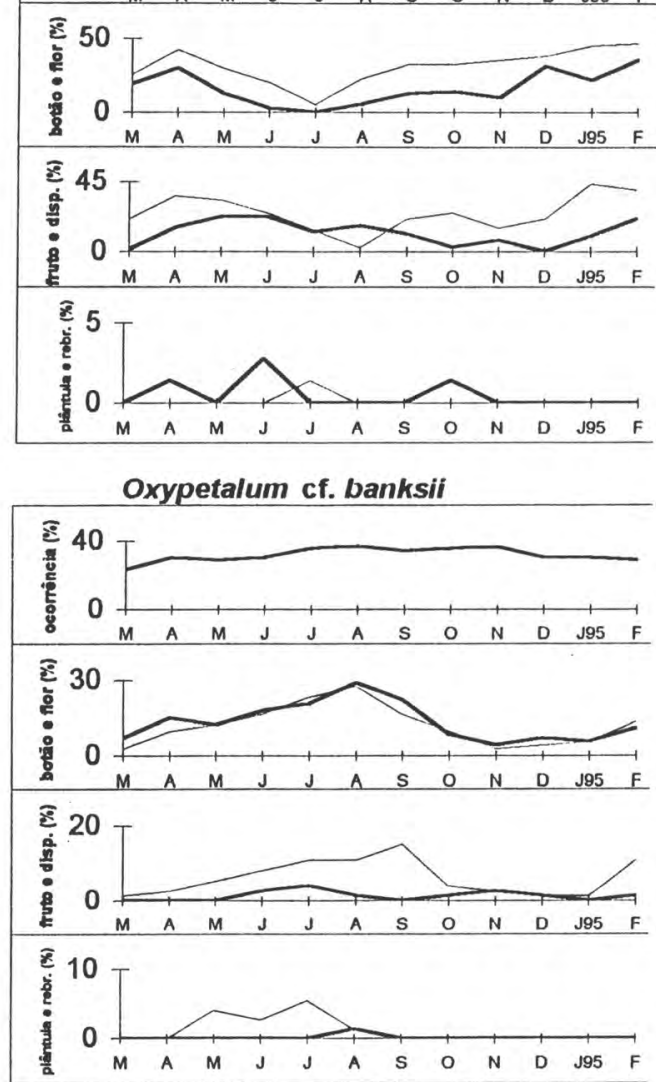

Blutaparon portulacoides
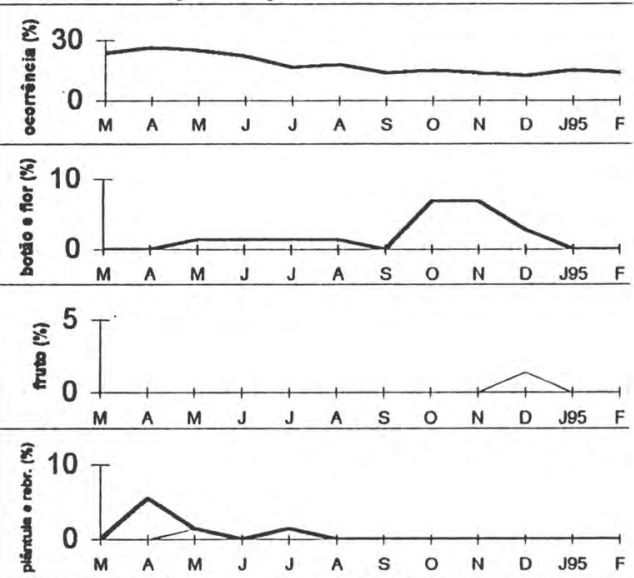

Figura 4 (continuação). Fenograma para espécies de maior freqüência de ocorrência (>25\%) e com episódios de floração de duração longa, duna frontal da Praia da Joaquina, Florianópolis, SC. As figuras apresentam a freqüência de ocorrência de cada espécie nas diferentes fenofases: floração (botão — e ântese floral — ); frutificação (frutos em desenvolvimento e maduros - e frutos em dispersão — ) ; germinação (expresso em frequêencia de ocorrência de plântulas — - ) e eventos de rebrota - . 
Tahela 5. Fenograma para eventos de rebrota nas espécies de duna frontal da Praia da Joaquina. Florianópolis. SC. As espécies estão organizadas de acordo com a duração dos episódios de rebrota na população: hreve $(<1$ mês), intermediária $(\geq 1$ a $<5$ meses $)$ e longa ( $\geq 5$ meses)

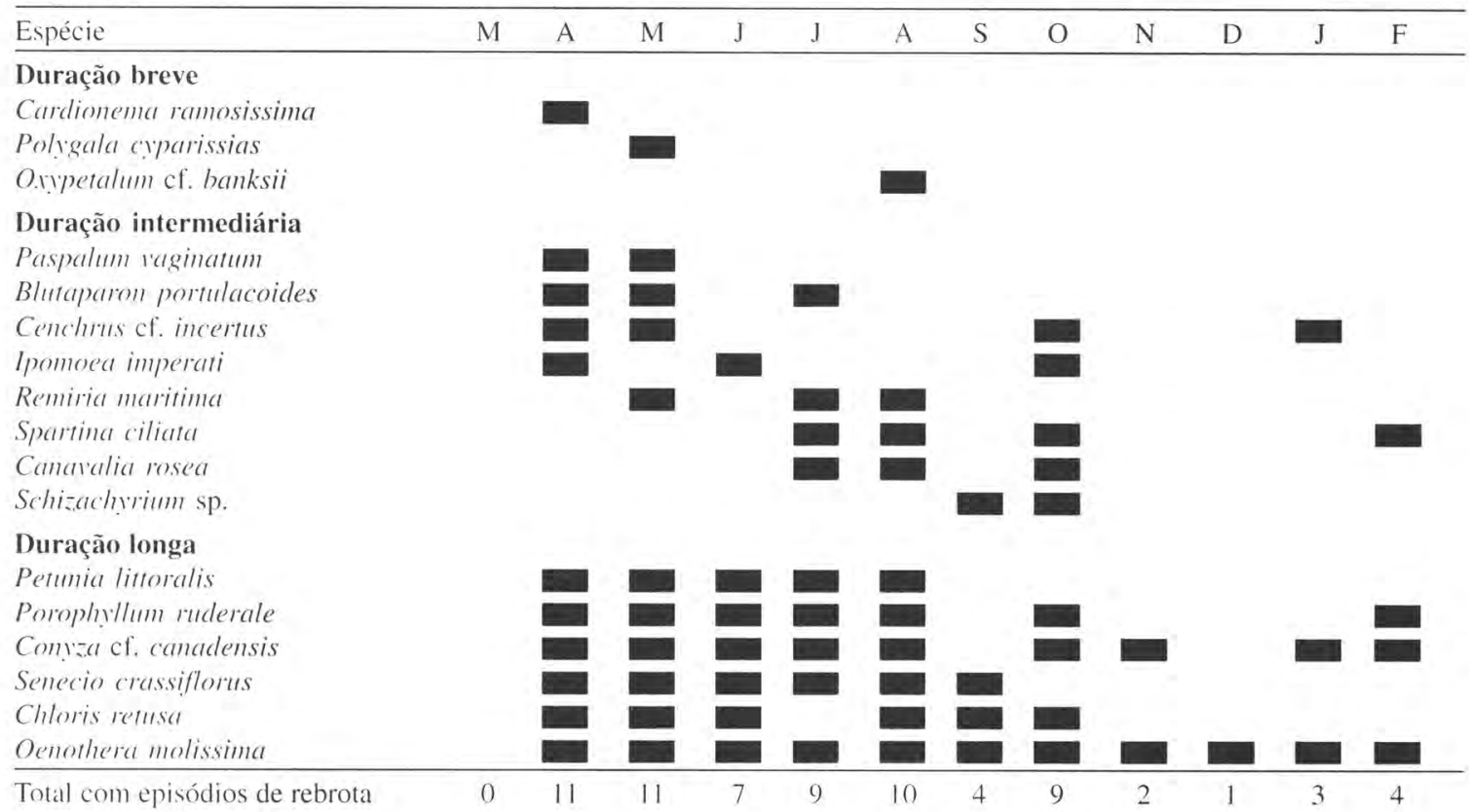

frutificação. Em Oenothera molissima, tal processo ocorreu durante 12 meses, sendo mais evidente de maio a outubro, após floração e frutificação (Figs. 3 e 4).

\section{Discussão}

A comunidade estudada mostrou tendência de maior floração de espécies no período quente e super-úmido, e menor floração no período mais frio, com redução de umidade. Em relação à umidade, Castillo \& Carabias (1982) descrevem para uma formação de dunas costeiras no México maior floração de espécies na estação chuvosa e menor florescimento em períodos com redução de pluviosidade. Na comunidade ora em estudo, a redução da floração pode estar relacionada à menor umidade e aos déficits hídricos registrados, mas pode refletir, também, certa limitação à floração pela redução de temperatura e fotoperíodo (Cordazzo \& Seeliger 1988). Na comunidade de dunas estudada por estes autores, no Rio Grande do Sul, a floração esteve positivamente correlacionada à temperatura e ao fotoperíodo. Ferri
(1979) e Larcher (1986) relatam que a temperatura é importante para a formação, desenvolvimento e abertura das flores e o fotoperíodo, para o início da floração.

Oxypetalum cf. banksii e Senecio crassiflorus apresentaram pico de floração no período frio, com menor umidade. Segundo Ferri (1979) e Larcher (1986), algumas espécies florescem após período de vernalização e outras, após passarem por restrição de umidade. A floração de algumas espécies no período de transição, assim como a própria floração de Senecio crassiflorus (setembro), podem refletir resposta mais rápida destas espécies aos aumentos de umidade, assim como os de elevação de temperatura e fotoperíodo que ocorrem neste período.

Apesar das aparentes restrições à floração na comunidade em estudo, ocorreram espécies em flor ao longo de todo o ano, como observado nas comunidades de dunas em São Paulo e Espírito Santo (Hueck 1955; Pereira et al. 1992). Foi observada maior proporção de espécies florescendo nos meses de inverno, em relação ao registrado por 
Cordazzo \& Seeliger (1988) para o Rio Grande do Sul, assim como maior proporção de espécies com floração de longa duração. Porém, mesmo com ocorrência de floração em meses mais frios em Santa Catarina, muitas das espécies de floração longa reduziram suas amplitudes neste período, podendo ser a temperatura o fator limitante.

Assim como a floração, ocorreu frutificação ao longo de todo o ano na comunidade em estudo, similar ao registrado por Pereira et al. (1992), no Espírito Santo.

Na comunidade em estudo, a maioria das espécies frutificou no período quente e superúmido, refletindo os máximos de floração. Castillo \& Carabias (1982) descrevem maior número de espécies em frutificação nos períodos de maior precipitação, e menor número em período mais seco. Ocorreram, no entanto, outros padrões de frutificação no México, assim como na comunidade ora em estudo. A frutificação de Oxypetalum cf. banksii no inverno, por exemplo, pode estar relacionada à dispersão pelo vento, que são mais intensos neste período (Santos 1995). Castillo \& Carabias (1982) descrevem que espécies com diásporas dispersas pelo vento, apresentam frutos maduros na estação após as chuvas, quando os ventos são mais intensos naquela localidade.

A maior ocorrência de germinação no outono/inverno, em períodos de temperaturas mais amenas e ainda favorável, corroboram as idéias sugeridas em estudos com espécies de dunas em regiões temperadas: o outono/inverno é considerado período favorável ao estabelecimento das plântulas, em comparação ao verão, quando condições de elevadas temperaturas e evapotranspiração são consideradas estressantes (Ernst 1985; Rozijn \& Andel 1985). Outros estudos associam a época de germinação das espécies a períodos favoráveis de umidade (Westelaken \& Maun 1985a, 1985b; Groenendael 1986; Cordazzo \& Seeliger 1988). Na comunidade em estudo, condições favoráveis de pluviosidade foram registradas ao longo de todo o ano, com exceção dos meses de agosto e setembro. O decréscimo na ocorrência de plântulas em setembro pode refletir este déficit hídrico, que pode afetar a germinação, emergência e sobrevivência das plântulas. Maun
(1994) salienta, entretanto, que diversos padrões de germinação vêm sendo registrados em ambientes de dunas, sendo estes decorrentes tanto dos fatores ambientais, como do tipo de dormência das sementes de cada espécie.

Quanto ao processo de rebrota, este foi mais freqüente num período similar ao de maior ocorrência de germinação. Nas dunas costeiras do Rio Grande do Sul, o brotamento vegetativo em espécies perenes ocorre no outono e primavera, estando positivamente correlacionado à precipitação (Cordazzo \& Seeliger 1988). No México, Castillo \& Carabias (1982) descrevem a estação chuvosa como a de maior produção de folhas jovens. $\mathrm{Na}$ área em estudo, o processo de rebrota ocorreu sob condições favoráveis de umidade, apresentando efeitos de inibição pelo déficit hídrico de setembro.

Para algumas espécies da comunidade estudada, a floração, frutificação e germinação foram fenômenos muito conspícuos, enquanto que para outras, como Panicum racemosum e Spartina cilicita, observou-se baixa ocorrência de plantas reprodutivas e total ausência de plântulas. No Rio Grande do Sul, Pfadenhauer (1978) e Costa et al. (1984, 1991) relataram que Panicum racemosum pode apresentar baixo vigor reprodutivo em dunas que estejam mais estabilizadas, e que este vigor varia em função dos distintos habitats de duna. Outras espécies consideradas "construtoras de dunas", como o são Panicum racemosum e Spartina ciliata, mostram este comportamento e podem manter-se localmente apenas por propagação vegetativa (Maun 1985). Entretanto, a importância da reprodução sexuada não deve ser generalizada como secundária, pois muitas "construtoras" dependem de sementes para regeneração populacional (Johnson 1985; Maun 1985). Os riscos na fase de emergência e estabelecimento de plântulas são, entretanto, muito elevados, principalmente na duna frontal, com maiores distâncias ao lençol freático, ríscos de mobilidade e erosão (Maun 1994).

Sugere-se, pelo presente estudo, que episódios de déficit hídrico restringem os eventos de floração e frutificação bem como os de germinação e brotamento. Na latitude em questão, a redução de temperatura parece limitar a floração, porém de forma menos intensa que no extremo 
sul do país (RS: $32^{\circ} \mathrm{S}$ ). A ocorrência de espécies em flor ao longo de todo o ano e maior proporção de espécies com floração de longa duração aproximam as características da comunidade estudada àquelas de dunas costeiras situadas em menores latitudes (SP: $24^{\circ} \mathrm{S}$ e ES: $20^{\circ} \mathrm{S}$ ).

\section{Agradecimentos}

À Ana Cláudia Araújo, Ana Zanin, Daniel B. Falkenberg, Hermógenes F. Leitão-Filho (em memória) e Ilse Boldrini pela identificação do material botânico. À Fernanda F. d'Eça Neves pelas sugestões na versão final do texto. Ao CNPq, pela concessão de bolsa a César Antonio Caus (Processo: 800125/87-8).

\section{Referências bibliográficas}

Castillo. S. \& Carabias, J. 1982. Ecologia de la vegetación de dunas costeras: fenologia. Biotica 7(4): 551-567.

Cordazzo C. V. \& Seeliger, U. 1988. Phenological and biogeographical aspects of coastal dune plant communities in southern Brazil. Vegetatio 75: 169-173.

Cordazzo. C. V. \& Seeliger, U. 1993. Zoned habitats of southern Brazilian coastal foredunes. Journal of Coastal Research 9(2): 317-323.

Costa, C. S. B.: Seeliger, U. \& Cordazzo, C. V. 1984. Aspectos da ecologia populacional do Panicum racemosum (Spreng.) nas dunas costeiras do Rio Grande do Sul, Brasil Pp. 395-411. In L. D. Lacerda: D. S. D. Araújo: R. Cerqueira \& B. Turcq. (ed.), Restingas: Origem, Estrutura, Processos. CEUFF, Niterói.

Costa, C. S. B.: Seeliger, U. \& Cordazzo, C. V. 1988a. Dinâmica populacional e distribuição horizontal de Androtrichum trigynum (Spreng.) Pfeiffer (Cyperaceae) em brejos e dunas costeiras do Rio Grande do Sul, Brasil. Acta Limnologica Brasileira 11: 81,3-842.

Costa. C. S. B.: Seeliger, U. \& Cordazzo, C. V. 1988 b. Distribution and phenology of Andropogon arenaritus Hackel on coastal dunes of Rio Grande do Sul, Brazil. Revista Brasileira de Biologia 48(3): 527-536.

Costa. C. S. B.: Seeliger, U. \& Cordazzo, C. V. 1991. Leaf demography and decline of Panicum racemosum populations in coastal foredunes of southern Brazil. Canadian Journal of Botany 69: 1593-1599.

d’Eça-Neves, F. F. \& Castellani, T. T. 1994. Fenologia e aspectos reprodutivos de Paepalanthus polyanthus (Bong.) Kunth (Eriocaulaceae) em baixada úmida entre dunas na Praia da Joaquina, Ilha de Santa Catarina, SC. Insula 23: 121-149.

Enst. W. H. O. 1985. Some considerations of and perspectives in coastal ecology. Vegetatio 62: 533-545.

Ferri. M. G. 1979. Fisiologia vegetal 2. EPU/EDUSP. São Patulo.
Groenendael. J. M. Van 1986. Life history characteristics of two ecotypes of Plantago lanceolata L. Acta Botanica Neerlandica 35(2): 71-86.

Hueck. K. 1955. Plantas e formação organogênica das dunas no litoral paulista - Parte 1. Instituto de Botânica. São Paulo.

Johnson. A. F. 1985. Ecologia de Abronia maritima, especie pionera de las dunas del oeste de Mexico. Biotica 10(1):19-34.

Larcher. W. 1986. Ecofisiologia vegetal. EPU, São Paulo.

Maun. M. A. 1985. Population biology of Ammophila brevilizulata and Calamovilfa longifolia on Lake Huron sand dunes. I. Habitat, growth form, reproduction, and establishment. Canadian Journal of Botany 63: 113-124.

Maun. M. A. 1994. Adaptations enhancing survival and establishment of seedlings on coastal dune systems. Vegetatio 111: 59-70.

Mendonça. E. N. \& Castellani, T. T. 1993. Aspectos da ecologia populacional de Drosera brevifolia Pursh em 1 m trecho de baixada úmida de dunas, Florianópolis. SC. Biotemas 6(1): 31-48.

Newstrom, L. E. \& Frankie, G. W. 1994. A new classification for plant phenology based on flowering patterns in lowland tropical rain forest trees at La Selva, Costa Rica. Biotropica 26(2): 141-159.

Pereira. O. J.: Thomaz. L. D. \& Araújo, D. S. D. de. 1992. Fitossociologia da vegetação de ante dunas da restinga de Setiba/Guarapari e em Interlagos/Vila Velha, ES. Boletim do Museu de Biologia Mello Leitão 1: 65-75.

Pfadenhater. J. 1978. Contribuição ao conhecimento da veggetação e de suas condições de crescimento nas dunas costeiras do Rio Grande do Sul, Brasil. Revista Brasileira de Biologia 38(4): 827-836.

Rathcke. B. \& Lacey, E. P. 1985. Phenological patterns of terrestrial plants. Annual Review of Ecology and Systematics 16: 179-2/4.

Rozijn. N. A. M. G. \& Andel, J.Van 1985. Analysis of the germination syndrome of dune annuals. Flora 177: 175-185.

Santos. C. R. 1995. Interrelação entre a dinâmica da vegetação "pioneira" e os padrões morfosedimentológicos sazonais na Praia da Joaquina, Ilha de Santa Catarina, Brasil. Dissertação de Mestrado. UFSC. Florianópolis.

Santos. C. R. \& Arruda, V. L. V. 1995. Floração, predação de flores e frutificação de Ipomoea pes-caprae e I. imperati (Convolvulaceae) na praia da Joaquina, SC. Insula 24: 15-36.

Souza. M. L. R. S.. Falkenberg, D. B., Amaral, L. G., Fronza. M.. Araụjo. A. C. \& Sá, M. R. 1991/1992. Vegetação do Pontal da Daniela, Florianópolis, SC. Brasil. I. Levantamento florístico e mapa fitogeográfico. Insula 21: 87-117.

Westelaken. 1. L. \& Maun, M. A. 1985a. Spatial pattern and seed dispersal of Lithospermum carolinense on Lake Huron sind dunes. Canadian Journal of Botany 63: 125-132.

Westelaken. 1. L. \& Maun, M. A. 1985b. Reproductive capacity. germination and survivorship of Lithospermum carolinense on Lake Huron sand dunes. Oecologia 66: $238-245$

Walter. H. 1986, Vegetação e zonas climáticas: Tratado de Ecologia Global. EPU. São Paulo. 